\title{
Experimental Studies about Characteristics of the Rocks Displacement and State of Bearing Pressure on the Haulage Roadway
}

\author{
Duc Thang Pham ${ }^{1, *}$, Hung Thang Hoang ${ }^{1}$, and Victor Vitcalov ${ }^{2}$ \\ ${ }^{1}$ Quang Ninh University of Industry, Quang Ninh, Vietnam \\ ${ }^{2}$ National University of Science and Technology MISiS, Moscow, Russia
}

\begin{abstract}
Comprehensive studies were conducted using measuring stations to measure the rock pressure and displacements of the roof rocks in the mine workings adjacent to the face when extracting medium thick inclined coal seams with the use of longwall (seam 6 at the Quang Hanh mine of Quang Ninh coal basin, Vietnam). The results of the study show that the displacement of the roof rock on the parallel roadway increases sharply at a distance of 1 to $12 \mathrm{~m}$ to the face, varies from 20 to $40 \mathrm{~mm}$ when the mining depth of the coal seam is $200 \mathrm{~m}$ and the maximum rock pressure on the haulage roadway supports is located at a distance of 3-8 m ahead of the face and is from 14 to 16 tons ranges.
\end{abstract}

\section{Introduction}

Experimental studies are one of the main methods of obtaining scientific data. They are based on an experiment that is a scientifically formulated experience under conditions, allowing to follow its progress, control it and recreate it if necessary. The purpose of the experiment is to check the theoretical assumptions, as well as a wider and deeper study of the research subject [1-4]. On-site observations and measurements play first and foremost role in mining science. This situation is not accidental. Indeed, when studying the mining processes a large variety of influencing factors. It is due both to the great diversity and variability of mining and geological conditions, as well as variations in the modes of reference and parameters of mining works. In addition, mining works are continuously developing, and their front moves in space [5-7]. Therefore, although mining experimental studies are laborious and complex, without them it is impossible to identify the main determining factors of the studied processes and correctly set tasks for analytical studies and laboratory modelling $[8,9]$.

The study of the influence of mining and geological factors on the efficiency and safety of mining works at the same time studies the interaction of support with the massif is carried out with the purpose substantiation of the parameters to objectively evaluate the effects of technological processes on the work of working face. These parameters are based on determining the value and nature of formation of rock pressure along the width and

\footnotetext{
*Corresponding author: phamducthangmet@gmail.com
} 
length of the mining district, which are included in the calculation when justifying technological schemes [10-11]. Based on the above analysis, the authors determined the values of bearing pressure on the supports of haulage roadway along the length of the extraction district and displacement of roof and floor rocks of the coal seam when extracting medium thick inclined coal seams at the Quang Hanh mine of the Quang Ninh coal basin Vietnam.

\section{Determination of the displacement of the roof and the formation of bearing pressure on the mine workings}

Experimental studies were carried out on the development faces (haulage roadway, parallel roadway) at the Quang Hanh mine when extracting coal seams 6, the longwall was equipped with mechanized support "ZQY3600" and shearer "MG132/320W". The scheme of the experimental section from the mining plan of coal seam 6 and the location of the measuring stations for the roof displacement are shown in Fig. 1.

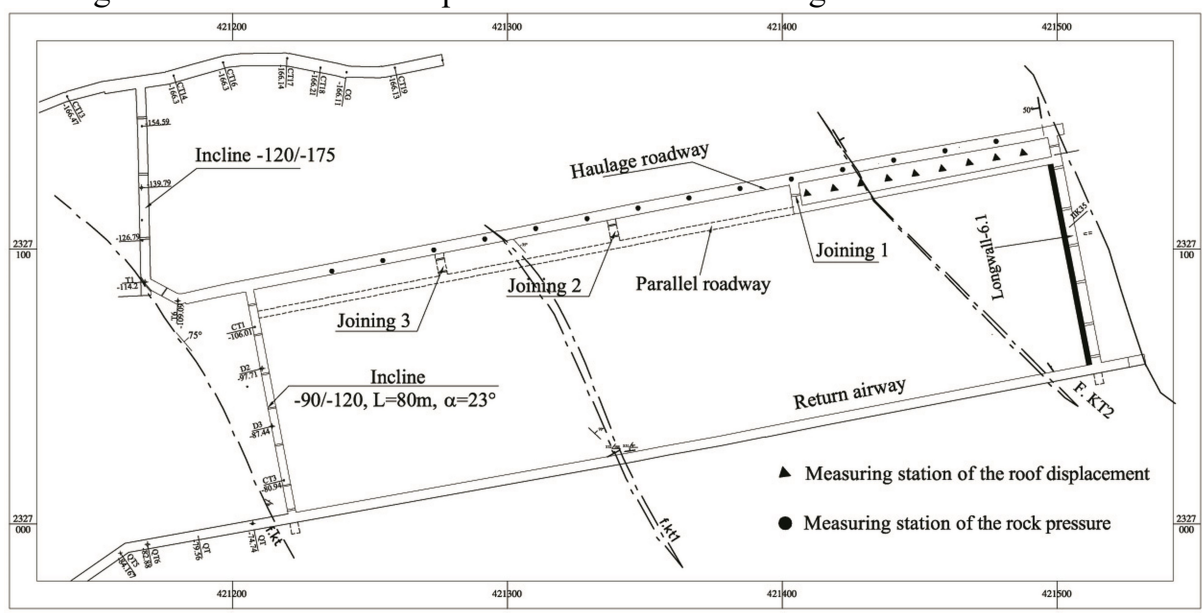

Fig. 1. Scheme location of the measuring stations in the haulage roadway and parallel roadway.

Mining and geological conditions of the seam 6 are as follows: thickness of coal seam $2,5 \mathrm{~m}$, dip of angle $20^{\circ}$, the strength of coal according to M.M. Protodyakonov is $f=1.5$, the density of coal is $1.6 \mathrm{~T} / \mathrm{m}^{3}$. The immediate roof of the coal seam 6 is represented by siltstone with medium strength, which is evenly distributed over the entire area of the seam thickness from 2.7 to $19.1 \mathrm{~m}$, average $9.4 \mathrm{~m}$ with the limit destruction strength $\sigma_{\mathrm{n}}=284$ $566 \mathrm{KG} / \mathrm{cm}^{2}$, average $409 \mathrm{KG} / \mathrm{cm}^{2}$, the density of the immediate roof $2.66 \mathrm{~T} / \mathrm{m}^{2}$. The main roof of the coal seam 6 is represented by thin-layer stable siltstone and sandstone with thickness from 7.7 to $15.5 \mathrm{~m}$, an average thickness $12.4 \mathrm{~m}$, compressive strength $\sigma_{\mathrm{n}}=858$ $\mathrm{KG} / \mathrm{cm}^{2}$, the main roof is characterized by stable. The immediate floor is siltstone and mudstone with medium strength, thickness from $1.7-8.6 \mathrm{~m}$ and compressive strength $\sigma_{\mathrm{n}}=$ $409 \mathrm{KG} / \mathrm{cm}^{2}$.

To measure the displacement of the roof in the parallel roadway adjacent to the longwall face, 9 measuring stations were installed along their length and with their distance of $9.8 \mathrm{~m}$. The layout of the stations for measuring the displacement is shown in Fig.1.

Recently, in the mines of the Quang Ninh coal basin, measurements of rock pressure on the supports are carried out by an electronic self-recording instrument "LEO Record". This instrument has the following advantages: high measurement accuracy, strength and high safety. For continuous measurement control, a lithium battery is used, which allows to 
display the information on the computer which is connected to the program Logger 4.0 to process data online. A general view of the self-recording instrument with connection to a computer is shown in Fig.2.
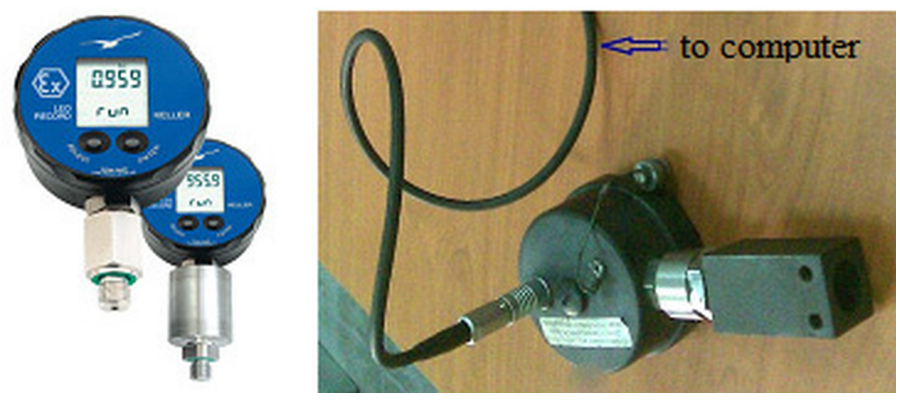

Fig. 2. Electronic self-recording instrument "LEO Record"

Measuring stations of rock pressure on the haulage roadway are located in front of the working face along the strike in the direction of coal mining with an installation distance of $20 \mathrm{~m}$. When the face approaches the first metering station, the metering station is transferred to the second metering station, located $20 \mathrm{~m}$ from the first station (Fig. 1.).

The measurement station for the study of rock pressure on the haulage roadway consists of an individual hydraulic support and an electronic self-recording manometer "LEO Record". The scheme of the measuring stations for the studies of rock pressure is shown in Fig.3.

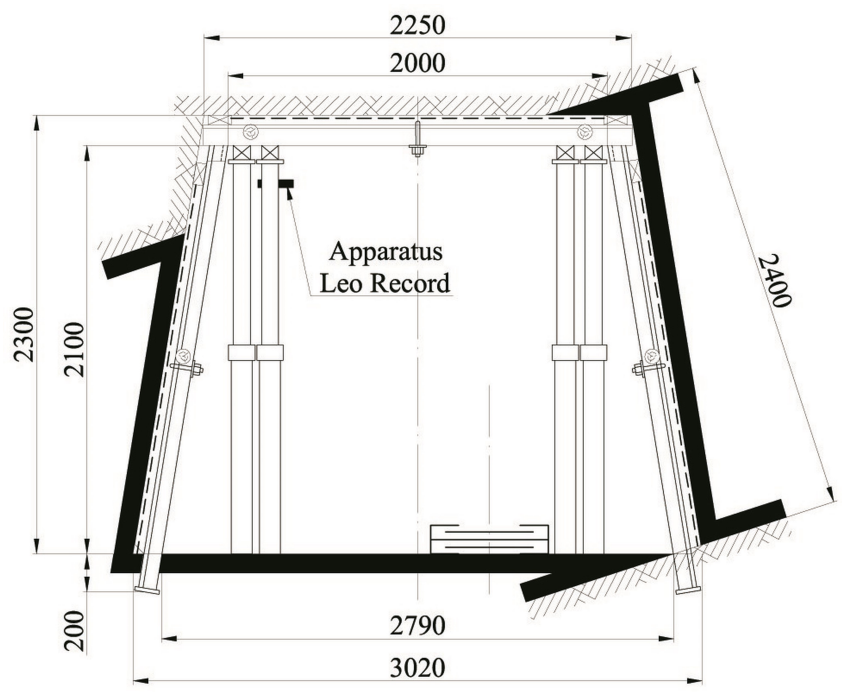

Fig. 3. The position of the measuring instrument "LEO Record" in the haulage roadway

According to the results of the study for the displacement of roof rocks by height, width and area on the parallel roadway, we constructed curves reflecting the characters of the displacement level of rocks (Fig. 4, Fig. 5, Fig. 6).

Processing the results of the study by the method of mathematical statistics (Fig. 4, Fig. 5 , Fig. 6) shows that the curve constructed from the results of mining studies is fairly objectively approximated by equations of the form:

The displacement by the height of the parallel roadway:

$$
y_{1}=5 E-08 x_{1}^{5}-1 E-05 x_{1}^{4}+0.0003 x_{1}^{3}+0.0313 x_{1}^{2}-2.2678 x_{1}+44.78
$$

The displacement by the width of the parallel roadway: 


$$
y_{2}=-5 E-07 x_{2}^{5}+5 E-05 x_{2}^{4}-0.0052 x_{2}^{3}+0.2378 x_{1}^{2}-5.2251 x_{1}+47.008
$$

The displacement by the area of the parallel roadway:

$$
y_{3}=2 E-0.7 x_{3}^{6}-6 E-05 x_{3}^{5}+0.0073 x_{3}^{4}-0.4625 x_{3}^{3}+15.856 x_{3}^{2}-279.41 x_{31}+2001.8
$$

Where: $\mathrm{y}_{1} ; \mathrm{y}_{2} ; \mathrm{y}_{3}-$ The displacement by the height, width and area, $\mathrm{mm} ; \mathrm{x}_{1} ; \mathrm{x}_{2} ; \mathrm{x}_{3}$ - distance from the face, $m$.

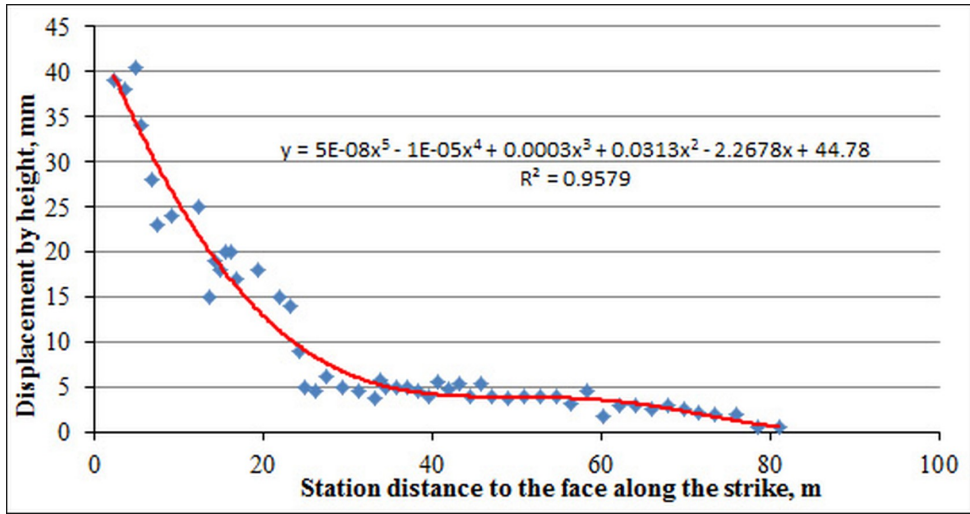

Fig. 4. Displacement of the roof rocks by height on the parallel roadway.

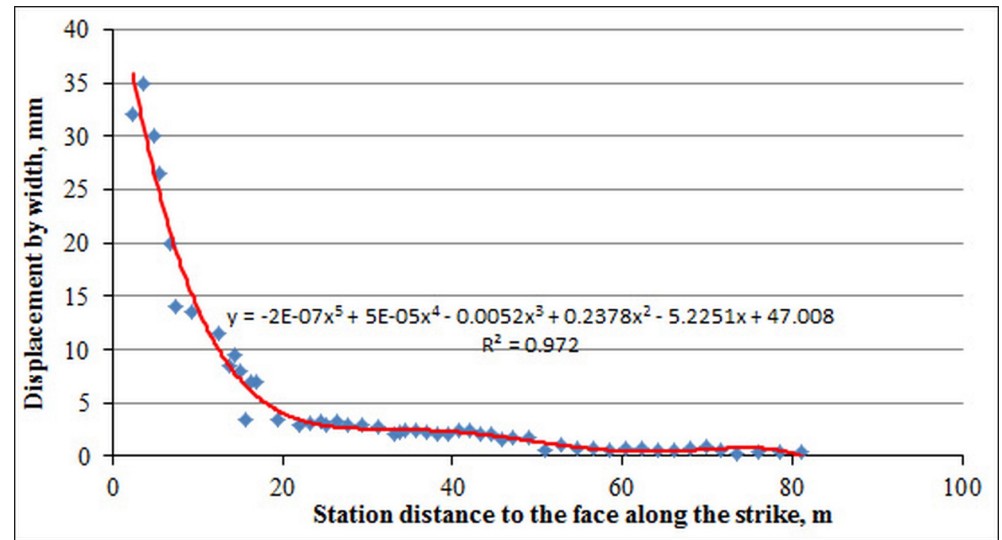

Fig. 5. Displacement of the roof rocks by width on the parallel roadway.

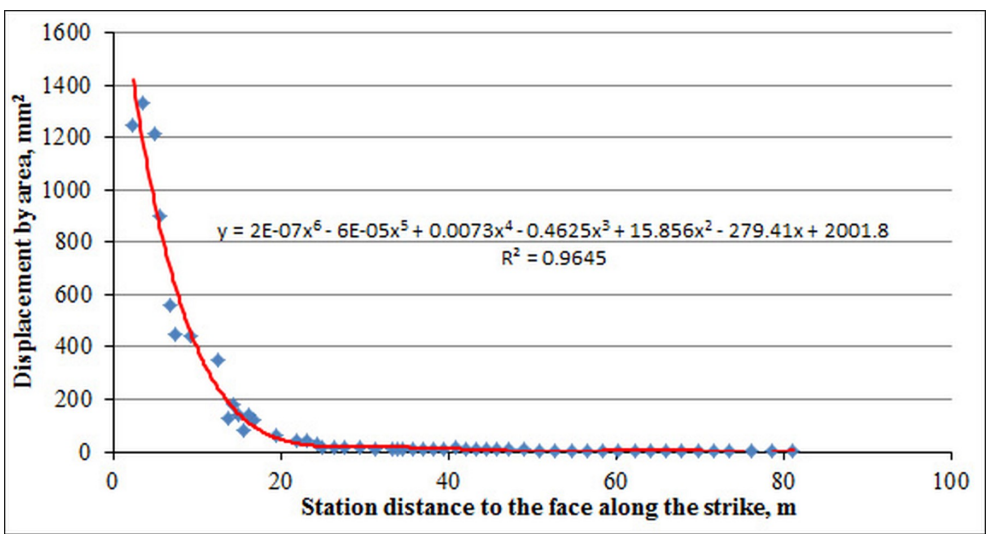

Fig. 6. Displacement of the rocks by area on the parallel roadway. 
The results of measurements of the displacement of the roof rocks, (presented in Fig. 4, Fig. 5, Fig. 6), show that the rate of displacement of the roof to the parallel roadway increases when the distance from the measuring stations to the longwall face decreases. This value increases slowly at a distance of over $30 \mathrm{~m}$, and increases sharply at a distance from 1 to $12 \mathrm{~m}$ to the working face. These values generally do not cause difficulties for the ventilation process, transportation of equipment and materials, as well as for coal loading during mining works in the longwall.

Based on the analysis of the data obtained from the electronic instrument "LEO Record" a graph was drawn up describing the changes in load on the supports of the haulage roadway along the length of the extraction district. The results of measurements of the rock pressure on the support are presented in Fig.7.

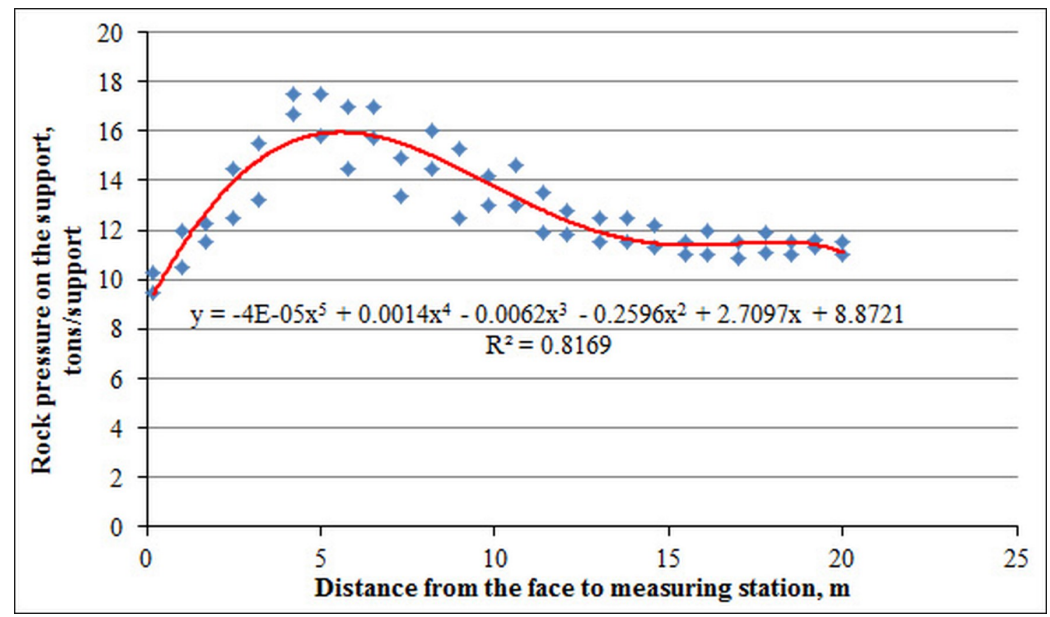

Fig. 7. The character of the formation of the rock pressure ahead of the face along the length of the haulage roadway.

Processing the results of the study by the method of mathematical statistics (Fig. 7) shows that the curve constructed from the results of mining studies is fairly objectively approximated by equations of the form:

$$
y=-4 E-05 x^{5}+0.0014 x^{4}-0.0062 x^{3}-0.2596 x^{2}+2.7097 x+8.8721
$$

Where: $\mathrm{y}$ - rock pressure, $\mathrm{MPa}$; $\mathrm{x}$-distance from the face, $\mathrm{m}$

The correlation coefficient is very high, which indicates a large narrowness of the connection between the parameters studied.

From Fig. 7 it can be seen that the bearing pressure on the support of the haulage roadway along the strike of the extracting area varies unevenly. The maximum of the bearing pressure is located at a distance of $3-8 \mathrm{~m}$ in front of the longwall and ranges from 14 to 16 tons. At a distance of $20 \mathrm{~m}$ from the face, the bearing pressure approaches the initial pressure, which does not contradict the earlier studies $[12,13]$.

\section{Conclusions}

Studies of the interaction of support with the massif are made with the purpose to obtain data for an objective assessment of the supporting work in specific mining and geological conditions and to study the influence of various factors on the supporting work during the whole service life of mine workings. They are based on establishing the value and character of the load distribution on the support with the purpose to clarify the design schemes when determining the durable dimensions of the supporting elements. 
On the basis of mining experimental and analytical studies, the character and speed of displacement of roof rocks along the length of preparatory mine workings were determined depending on the distance to the working face. According to the results of observations, the smaller the distance from the working face along the strike of the extracting area, the higher the speed of displacement of the roof rocks in the adjacent development workings, which at a distance from $1 \mathrm{~m}$ to $12 \mathrm{~m}$ to the face, varies respectively from 20 to $40 \mathrm{~mm}$ at working depth of $200 \mathrm{~m}$. Obtained quantitative power parameters of support, to ensure efficient and safe work in the studied range of mining and geological conditions.

The character of the formation of bearing pressure in front of the working face along the haulage roadway has been established, as well as its maximum and distances are determined. The maximum of bearing pressure is located at a distance of 3-8 $\mathrm{m}$ in front of the working face and ranges from 14-16 tons.

\section{References}

1. M. Tadeusz, N. Zbigniew, U. Artur Studia Geotechnica et Mechanica, 37, 45 (2015)

2. E.P. Bragin, V.G. Vitcalov, Pham Trung Nguyen, Mining informational and analytical bulletin Journal, 10, 37 (2010)

3. A. Arkady, S. Elena, R. Roman Problem of complex development of georesources (EDP Sciences, Paris, 2018)

4. Yanli Huang, Junmeng Li, Tianqi Song, Guoqiang Kong, Meng Li., Energies, 10, 23 (2017)

5. B.D. Terentev, V.V. Melnik, Geomechanical substantiation of underground mining works (MISIS, Moscow, 2016)

6. W.H.S. Daniel, Int. J. Min. Sci. Technol., 27, 15 (2017)

7. I. Kovalevs'ka, O. Vivcharenko, V. Snigur, Mining of Mineral Deposits, 10, 29 (2013)

8. G. Song, Y.P. Chugh The Journal of the Southern African Institute of Mining and Metalurgy, 118, 130 (2018)

9. A.V. Remezov, S.V. Novoselov, Ugol', 6, 21 (2018)

10. G. Symanovych, K. Ganushevych, New techniques and technologies in Mining (London, Taylor \& Francis, 2010)

11. Xu Hongjie, Xing Guofu and Xu Tianfa, Coal Science and Technology, 7, 40 (2012)

12. V.G. Vitcalov, Pham Duc Thang, Nguyen Anh Tuan, Mining informational and analytical bulletin Journal, 12, 5 (2017).

13. V.G. Vitcalov, Pham Trung Nguyen, Nguyen Anh Tuan, Mining Science and Technology, 4, 3 (2013) 